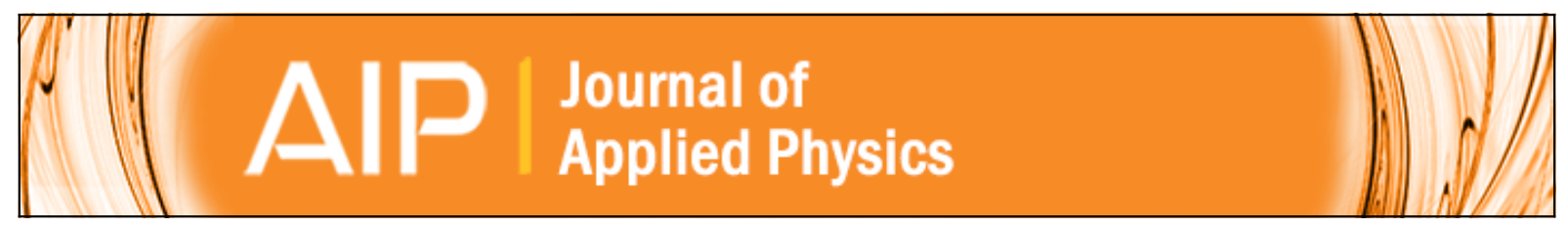

\title{
Lead-free high-temperature dielectrics with wide operational range
}

Robert Dittmer, Wook Jo, Dragan Damjanovic, and Jürgen Rödel

Citation: Journal of Applied Physics 109, 034107 (2011); doi: 10.1063/1.3544481

View online: http://dx.doi.org/10.1063/1.3544481

View Table of Contents: http://scitation.aip.org/content/aip/journal/jap/109/3?ver=pdfcov

Published by the AIP Publishing

\section{Articles you may be interested in}

Effect of composition on electrical properties of lead-free Bi0.5(Na0.80K0.20)0.5TiO3-(Ba0.98Nd0.02)TiO3 piezoelectric ceramics

J. Appl. Phys. 114, 027005 (2013); 10.1063/1.4811813

High T c lead-free Ba Ti O 3 - ( $\mathrm{Bi} 1 / 2 \mathrm{Na} \mathrm{1/2} \mathrm{)} \mathrm{Ti} \mathrm{O} 3$ positive temperature coefficient of resistivity ceramics with electrically heterogeneous structure

Appl. Phys. Lett. 91, 162904 (2007); 10.1063/1.2799878

Phase structure, microstructure, and electrical properties of bismuth modified potassium-sodium niobium leadfree ceramics

J. Appl. Phys. 102, 054102 (2007); 10.1063/1.2775997

Dielectric behavior and microstructure of ( $\mathrm{Bi} 1 / 2 \mathrm{Na} 1 / 2) \mathrm{TiO} 3-(\mathrm{Bi} 1 / 2 \mathrm{~K} 1 / 2$ ) TiO 3 - BaTiO 3 lead-free piezoelectric ceramics

J. Appl. Phys. 97, 104101 (2005); 10.1063/1.1890453

Electromechanical and ferroelectric properties of ( Bi 1/2 Na 1/2) TiO $3-(\mathrm{Bi} 1 / 2 \mathrm{~K} 1 / 2$ ) TiO $3-\mathrm{BaTiO} 3$ lead-free piezoelectric ceramics

Appl. Phys. Lett. 85, 91 (2004); 10.1063/1.1767592

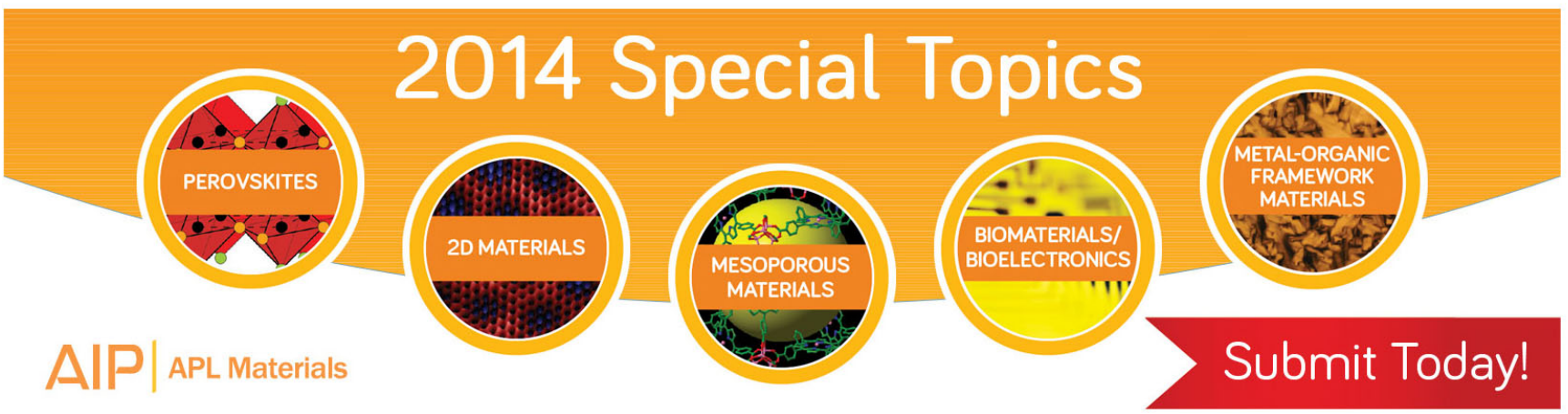




\title{
Lead-free high-temperature dielectrics with wide operational range
}

\author{
Robert Dittmer, ${ }^{1}$ Wook Jo, ${ }^{1, a)}$ Dragan Damjanovic, ${ }^{2}$ and Jürgen Rödel ${ }^{1}$ \\ ${ }^{1}$ Institute of Materials Science, Technische Universität Darmstadt, Petersenstr. 23, 64287 Darmstadt, \\ Germany \\ ${ }^{2}$ Ceramics Laboratory, Swiss Federal Institute of Technology, EPFL, 1015 Lausanne, Switzerland
}

(Received 25 October 2010; accepted 10 December 2010; published online 9 February 2011)

\begin{abstract}
The dielectric, electrical and structural properties of $(1-x)\left(0.94 \mathrm{Bi}_{1 / 2} \mathrm{Na}_{1 / 2} \mathrm{TiO}_{3}-0.06 \mathrm{BaTiO}_{3}\right)-$ $x \mathrm{~K}_{0.5} \mathrm{Na}_{0.5} \mathrm{NbO}_{3}(\mathrm{BNT}-\mathrm{BT}-x \mathrm{KNN})$ with $x=0.09,0.12,0.15$, and 0.18 were investigated as potential candidates for high-temperature capacitors with a working temperature far beyond $200{ }^{\circ} \mathrm{C}$. Temperature dependent dielectric permittivity $(\varepsilon)$ showed two local broad maxima that at the optimal composition of $\mathrm{KNN}(x=0.18)$ are combined to form a plateau. This then results in a highly temperature-insensitive permittivity up to $\sim 300{ }^{\circ} \mathrm{C}$ at the expense of a small reduction in absolute permittivity values. High-temperature in situ X-ray diffraction study showed pseudocubic symmetry without obvious structural changes, which implies that the dielectric anomalies observed could only be a consequence of a slight change in space group. BNT-BT-0.18KNN showed a permittivity of $\sim 2150$ at the frequency of $1 \mathrm{kHz}$ at $150{ }^{\circ} \mathrm{C}$ with a normalized permittivity $\varepsilon / \varepsilon_{150}{ }^{\circ} \mathrm{C}$ varying no more than $\pm 10 \%$ from 43 to $319^{\circ} \mathrm{C}$. With very good electrical properties persisting up to $300{ }^{\circ} \mathrm{C}$, i.e., a resistivity on the order of magnitude of $10^{8} \Omega \mathrm{m}$ and the $R C$ constant of about $1 \mathrm{~s}$, the examined BNT-BT- $x$ KNN compositions present a good starting point for the development of high-temperature capacitor materials. (C) 2011 American Institute of Physics.
\end{abstract}

[doi:10.1063/1.3544481]

\section{INTRODUCTION}

Capacitors are indispensable components for passive parts in contemporary electronic devices. They fulfill a variety of important functions including voltage smoothing, pulse discharge, filtering, dc blocking, coupling, decoupling, snubbing, and power conditioning. ${ }^{1,2}$ However, with increasing demands on the performance and efficiency of electronic systems, the requirements on capacitor materials imposed by the industries are increasing as well. The high-temperature electronics are of particular interest as control units are intended to be placed close to hot components, such as engines or transmissions. ${ }^{3,4}$ This allows a higher degree of integration, and thereby simplifies the assembly of the overall product (e.g., the vehicle) and saves cost and mass of thermal insulation and wiring. For their contribution to miniaturization, cost-effectiveness and lightweight design, hightemperature electronics are highly desired in automotive, aerospace, and defense technologies. ${ }^{5,6}$ In automotive industry the trend toward hybrid or electrically powered cars is pushing the temperature envelope even higher due to the increased integration of power electronics and the heat dissipation thereof. Other applications where electronics are required to operate at elevated temperatures include instrumentation for geothermal wells, oil well logging, and nuclear reactors. 4,5

In all these applications, the electric components have to operate under harsh conditions while maintaining good electrical properties and providing high reliability at temperatures beyond $200{ }^{\circ} \mathrm{C}$. Among the required passive devices, the capacitor is probably one of the most challenging com-

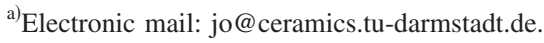

ponents. Materials are chosen for high permittivity at their phase transition with the attendant disadvantage that temperature dependence is high at these temperatures. ${ }^{7}$ However, a capacitor must operate with a relatively constant capacitance over the whole operational range. Moreover, a high permittivity is needed in order to make a large value capacitor, which is required for power conditioning circuits. ${ }^{5}$ If the volumetric efficiency of the dielectrics is too low, the capacitor becomes too large, and hence ill-suited for system miniaturization, or may even fail due to thermal stresses induced during thermal cycling. The development of a hightemperature capacitor is further impeded by resistivity and loss factor that also exhibit a strong dependence on temperature. A capacitor suited for high-temperature applications is required to exhibit high resistivity and low losses. Another constraint is the demand for low frequency dispersion of the capacitance and the loss factor. In addition to these technical requirements, the production of a mass market product like a capacitor has to be cost-effective. Therefore, the use of rare raw materials or unconventional production methods is not suitable for fabrication on a large scale.

Dielectrics that show good electrical properties at room temperature usually exhibit strongly reduced properties at elevated temperatures and thus are often limited to temperatures below $125^{\circ} \mathrm{C} .{ }^{8,9}$ Other dielectrics feature very high operational temperatures but either lack high permittivity or suffer from strong temperature dependence. ${ }^{10-12}$ Bridger et $a l .{ }^{13}$ showed that $0.9\left(\mathrm{Bi}_{1 / 2} \mathrm{Na}_{1 / 2}\right) \mathrm{TiO}_{3}-0.1 \mathrm{KTaO}_{3}$ exhibits a relatively flat permittivity from 80 to $260{ }^{\circ} \mathrm{C}$ though permittivity outside this range rapidly decreases. Lim et al. ${ }^{14}$ have shown that the $\mathrm{BiScO}_{3}-\mathrm{BaTiO}_{3}-\left(\mathrm{K}_{1 / 2} \mathrm{Bi}_{1 / 2}\right) \mathrm{TiO}_{3}$ (BSBTKBT) pseudoternary system exhibits good electrical properties over a wide temperature range. However, the large fre- 
quency dispersion at low temperatures presents a serious drawback. Moreover, BSBT-KBT incorporates the element scandium which is also found in other materials that had been suggested for high-temperature dielectrics. ${ }^{15,16}$ The extraordinarily high price of scandium, however, limits the use of such materials to academic research. With regard to a potential application, it is vital to incorporate only those raw materials that are widely available with a reasonable price.

Zhang et al. ${ }^{17}$ investigated $\left(\mathrm{Bi}_{1 / 2} \mathrm{Na}_{1 / 2}\right) \mathrm{TiO}_{3}-\mathrm{BaTiO}_{3}-$ $\left(\mathrm{K}_{0.5} \mathrm{Na}_{0.5}\right) \mathrm{NbO}_{3}$ (BNT-BT-KNN) pseudoternary systems mainly with respect to high electric field properties. Thereby, it was discovered that electric field induced phase changes cause large strain behavior in compositions with low KNNcontent rendering them suitable for actuators. Materials with higher amounts of KNN were found to exhibit high electrostrictive constants and temperature-insensitive field-induced strain which are attractive for high-precision positioning devices and other actuators. ${ }^{18}$

In this study, we report the electric and dielectric properties of $(1-x)[0.94 \mathrm{BNT}-0.06 \mathrm{BT}]-x \mathrm{KNN}$ with $x=0.09$, $0.12,0.15$, and 0.18 . The influence of the KNN-content on permittivity, loss factor, resistivity and structure was investigated for temperatures from 30 up to $400{ }^{\circ} \mathrm{C}$. We demonstrate that this material is promising as a dielectric for hightemperature applications owing to its very good dielectric and electric characteristics that can be achieved over a very broad operational temperature range.

\section{EXPERIMENTAL}

Ceramics were produced via a mixed oxide route using reagent grade oxides and carbonates (Alfa Aesar $\mathrm{GmbH} \&$ Co. KG, Karlsruhe, Germany). First, $\mathrm{Bi}_{2} \mathrm{O}_{3}(99.975 \%)$, $\mathrm{Na}_{2} \mathrm{CO}_{3}(99.5 \%), \mathrm{TiO}_{2}(99.9 \%), \mathrm{BaCO}_{3}(99.8 \%), \mathrm{K}_{2} \mathrm{CO}_{3}$ $(99.0 \%)$, and $\mathrm{Nb}_{2} \mathrm{O}_{5}(99.9 \%)$ were mixed according to the stoichiometric formula and ball-milled in a planetary ballmill (Fritsch Pulverisette 5, Idar-Oberstein, Germany) for 24 $\mathrm{h}$ at $250 \mathrm{rpm}$ with zirconia balls in ethanol. After drying at $100{ }^{\circ} \mathrm{C}$, the mixed powder was calcined at $900{ }^{\circ} \mathrm{C}$ for $3 \mathrm{~h}$, and subsequently ball-milled again for $24 \mathrm{~h}$. Pestled and sieved powders were compacted into pellets of $10 \mathrm{~mm}$ in diameter. To facilitate the densification, powder compacts were hydrostatically pressed under $300 \mathrm{MPa}$. Sintering was performed at $1100{ }^{\circ} \mathrm{C}$ for $3 \mathrm{~h}$ in a covered alumina crucible with atmospheric powder of the same composition to minimize the loss of volatile elements. Finally the sintered pellets were ground, and polished. Samples were electroded with a silver paint on both sides and fired at $400{ }^{\circ} \mathrm{C}$ for $30 \mathrm{~min}$.

Dielectric measurements were carried out with a HP4192A impedance analyzer (Hewlett-Packard Co., Pala Alto, CA, USA) using a Nabertherm LE4/11/R6 furnace (Nabertherm GmbH, Lilienthal, Germany) with a homemade sample holder at a heating rate of $2 \mathrm{~K} \mathrm{~min}^{-1}$. The leakage current was measured by means of a Keithley 6517B high resistance meter and a home-made furnace at a ramping rate of $4 \mathrm{~K} \mathrm{~min}^{-1}$ up to $400{ }^{\circ} \mathrm{C}$ under a dc voltage of $60 \mathrm{~V}$. The $R C$ constant was calculated from the capacitance at 1 $\mathrm{kHz}$ and the dc resistance.

Density was determined via the Archimedes method. For

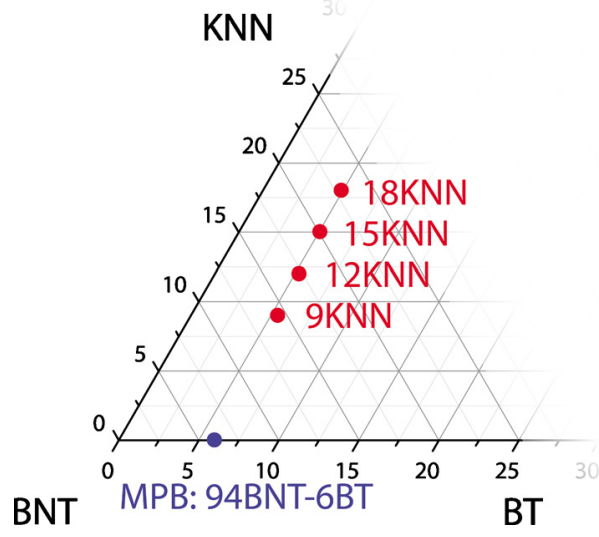

FIG. 1. (Color online) Illustration of the compositions studied.

the microstructural analysis, samples were polished with diamond paste down to $0.25 \mu \mathrm{m}$ and coated with a thin layer of carbon for subsequent observation in the scanning electron microscope L30 FEG/ESEM (Philips/FEI, Hillsboro, OR, USA). The average grain size was determined from the mean intercept length multiplied by 1.56 . Room temperature structure was characterized by a powder x-ray diffraction (XRD, STADI P STOE, Darmstadt, Germany) with a transmission geometry using $\mathrm{Cu} K \alpha_{1}$ radiation. To release stress induced during the sample preparation stage, the crushed powders were thermally annealed at $400{ }^{\circ} \mathrm{C}$ for $1 \mathrm{~h}$. For the temperature dependent structural analysis, a reflective XRD apparatus (Bruker AXS D8, Karlsruhe, Germany) equipped with a furnace was employed using $\mathrm{Cu} K \alpha$ radiation.

\section{RESULTS AND DISCUSSION}

Figure 1 illustrates a segment of the pseudo-ternary phase diagram of the BNT-BT-KNN system showing the location of the four compositions examined. These are $(1-x)$ $\times[0.94 \mathrm{BNT}-0.06 \mathrm{BT}]-x \mathrm{KNN}$ with $x=0.09,0.12,0.15$, and 0.18 , which will be termed $9 \mathrm{KNN}, 12 \mathrm{KNN}, 15 \mathrm{KNN}$, and $18 \mathrm{KNN}$ in the following. Note that all four compositions are a derivative of the base composition 0.94BNT-0.06BT, which lies at the morphotropic phase boundary between rhombohedral BNT and tetragonal BT. ${ }^{19}$ Using roomtemperature XRD, it was confirmed that all four compositions were successfully synthesized as single phase materials that show pseudocubic structure.

The average grain size $\mathrm{G}$ and the relative density $\rho$ of the materials studied are summarized in Table I. The KNN content has little influence both on the density and on the average grain size. All four specimens showed a very homogeneous microstructure with practically the same average grain

TABLE I. Average grain size, G, and relative density, $\rho$.

\begin{tabular}{lcc}
\hline \hline & $\begin{array}{c}\mathrm{G} \\
(\mu \mathrm{m})\end{array}$ & $\begin{array}{c}\rho \\
(\%)\end{array}$ \\
\hline $9 \mathrm{KNN}$ & $0.5 \pm 0.1$ & $98 \pm 0.5$ \\
$12 \mathrm{KNN}$ & $0.5 \pm 0.1$ & $98 \pm 0.3$ \\
$15 \mathrm{KNN}$ & $0.6 \pm 0.1$ & $98 \pm 0.7$ \\
$18 \mathrm{KNN}$ & $0.5 \pm 0.1$ & $96 \pm 0.3$ \\
\hline \hline
\end{tabular}




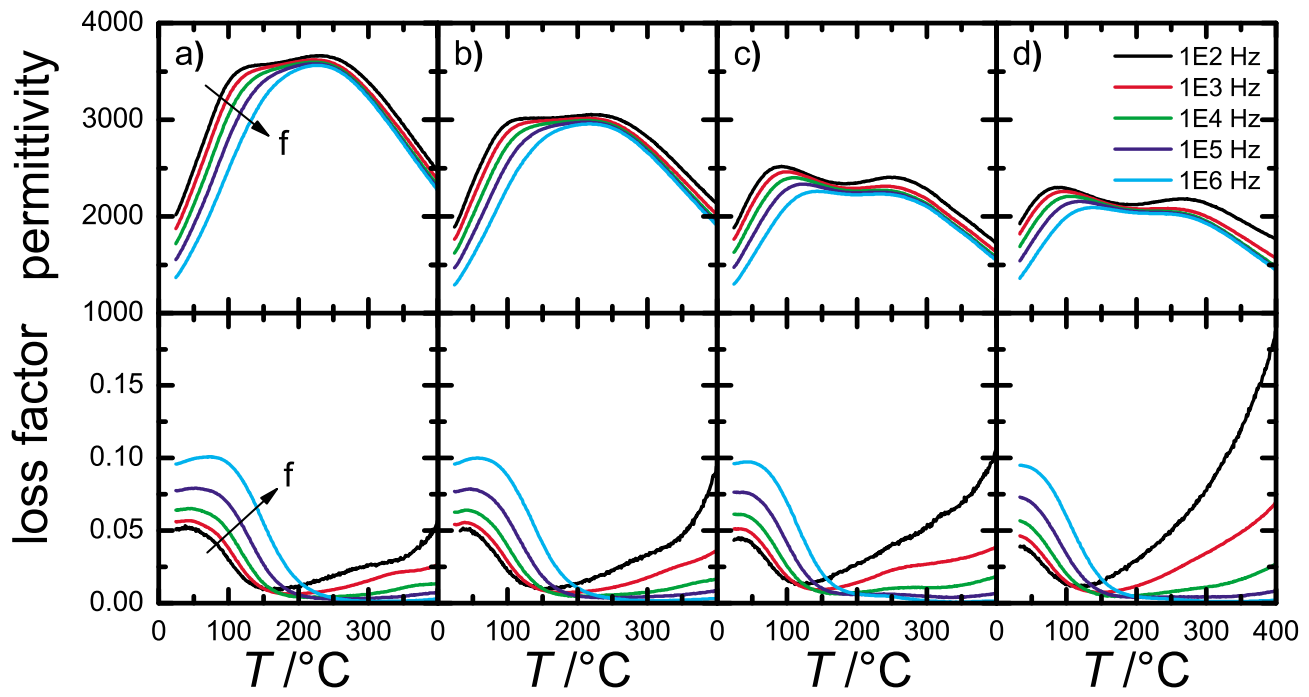

FIG. 2. (Color online) Permittivity and loss factor for (a) $9 \mathrm{KNN}$, (b) $12 \mathrm{KNN}$, (c) $15 \mathrm{KNN}$, and (d) $18 \mathrm{KNN}$ at different frequencies.

size of $\approx 0.5 \mu \mathrm{m}$, and the relative density of $>96 \%$. The fact that fairly dense specimens with submicron-sized grains are available by a conventional sintering technique in the current system is highly promising from the industrial point of view, since it is an essential prerequisite for mass production and miniaturization of multilayer ceramic capacitors.

Figure 2 provides the temperature dependent dielectric permittivity and loss factor from room temperature up to $400{ }^{\circ} \mathrm{C}$ for all the compositions studied. Two distinctive dielectric anomalies are discerned common to BNT-based materials. ${ }^{20}$ The first dielectric anomaly at $\approx 100{ }^{\circ} \mathrm{C}$ involves a frequency dependent dielectric permittivity, which is known as one of the distinctive features characterizing relaxor ferroelectrics. ${ }^{21-23}$ In fact, the changes in loss tangent also support the assumption that the material has relaxor characteristic. $^{24}$ The other dielectric anomaly appears at $\approx 250{ }^{\circ} \mathrm{C}$ showing neither frequency dispersion nor abrupt changes in loss factor. Comparison of the plots for all the compositions investigated clearly rationalizes the effect of $\mathrm{KNN}$ which is to render the permittivity values insensitive to temperature. Here, the temperatures that designate the first and the second dielectric anomaly are referred to as $\mathrm{T}_{\mathrm{m} 1}$ and $\mathrm{T}_{\mathrm{m} 2}$, respectively, and are summarized in Fig. 3. It is demonstrates that $\mathrm{T}_{\mathrm{m} 1}$ decreases while $\mathrm{T}_{\mathrm{m} 2}$ increases with in-

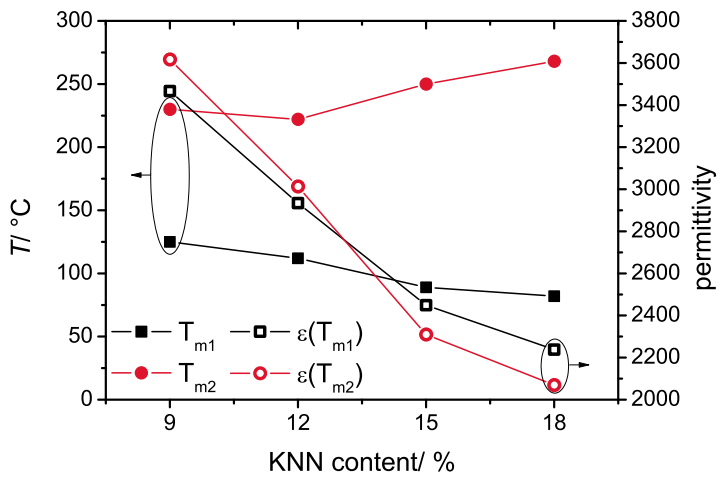

FIG. 3. (Color online) Evolution of characteristic temperatures and permittivity values with $\mathrm{KNN}$ content (data at $1 \mathrm{kHz}, \mathrm{T}_{\mathrm{m} 1}$ and $\mathrm{T}_{\mathrm{m} 2}$ derived from first derivative of permittivity). creasing KNN content. At the same time, the permittivity values at both temperatures are reduced. The increase in $\Delta \mathrm{T}\left(=\mathrm{T}_{\mathrm{m} 2}-\mathrm{T}_{\mathrm{m} 1}\right)$ and the reduction in the permittivity values are responsible for the expansion of the range of working temperature and for the temperature insensitivity, respectively. Feasibility of the studied materials as high temperature dielectrics is further quantified in Fig. 4

The permittivity normalized to the permittivity at $150{ }^{\circ} \mathrm{C} \varepsilon / \varepsilon_{150}{ }^{\circ} \mathrm{C}$ is plotted at $1 \mathrm{kHz}$. The dotted and the dashed frames indicate the operational ranges with $\pm 5 \%$ and $\pm 10 \%$ tolerance, respectively. For $\pm 5 \%$ tolerance the operational range increases from $109-292{ }^{\circ} \mathrm{C}$ to $53-294{ }^{\circ} \mathrm{C}$. This is a remarkably flat progression of the permittivity considering that there is less than 5\% variation in a range that spans over $240 \mathrm{~K}$, reaching almost $300{ }^{\circ} \mathrm{C}$ in $18 \mathrm{KNN}$. For a $\pm 10 \%$ tolerance the working temperature spans from $96-313{ }^{\circ} \mathrm{C}$ in $9 \mathrm{KNN}$ to $43-319{ }^{\circ} \mathrm{C}$ in $18 \mathrm{KNN}$. This small deviation in permittivity is a notable feature since the Electronic Industries Alliance (EIA) permits $\pm 15 \%$ deviations for commercially available X7R capacitors that are currently designated for operation at elevated temperatures.

Albeit limited to $125^{\circ} \mathrm{C}$, those X7R materials exhibit advantages at low temperatures down to $-55{ }^{\circ} \mathrm{C}$. In contrast, the permittivity of the materials presented here decreases gradually when the temperature drops below $\mathrm{T}_{\mathrm{m} 1}$. Therefore, it would be beneficial to shift $\mathrm{T}_{\mathrm{m} 1}$ below room temperature, e.g., by means of additional chemical substitutions. This

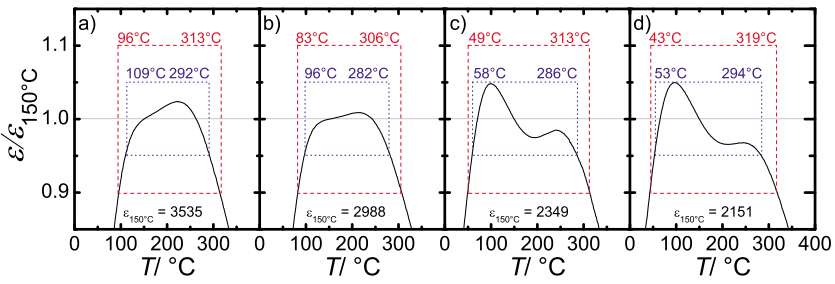

FIG. 4. (Color online) Change in permittivity at $1 \mathrm{kHz}$ (at $150{ }^{\circ} \mathrm{C}$ ) and illustration of operational range for deviation of $\pm 5 \%$ (dotted frame) and $\pm 10 \%$ (dashed frame) for (a) $9 \mathrm{KNN}$, (b) $12 \mathrm{KNN}$, (c) $15 \mathrm{KNN}$, and (d) $18 \mathrm{KNN}$. 


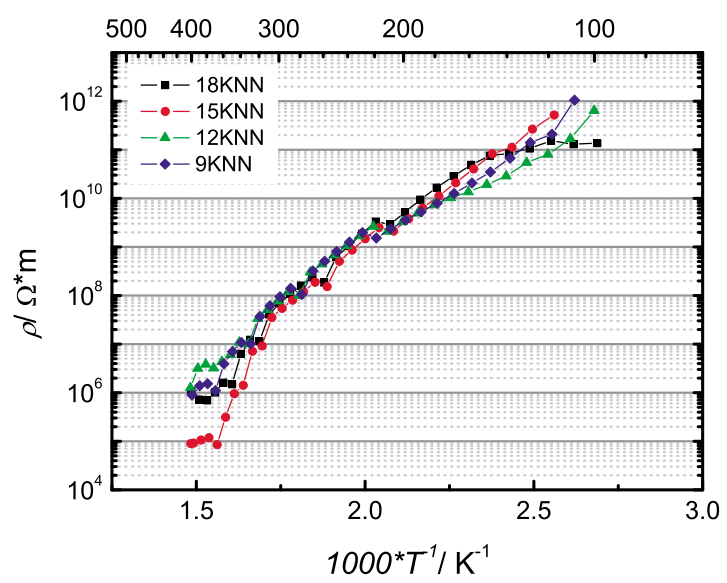

FIG. 5. (Color online) Resistivity as function of inverse absolute temperature measured at $60 \mathrm{~V}_{\mathrm{dc}}$.

could not only expand the operational temperature range but potentially also may eliminate the frequency dispersion at room temperature.

High permittivity, temperature stability, and low loss are not the only key figures; for the application as a capacitor, the dielectric material is required to have both high resistivity and RC constant even at elevated temperatures. Although an ideal capacitor would have an infinite resistivity, all real capacitors have a finite value for its resistivity. Hence, a charged capacitor will have a leakage current and will discharge through its own resistance. Because of this, a capacitive device of higher performance is obtained by higher resistivity. ${ }^{25}$ Figure 5 illustrates that resistivity is very similar among the four BNT-BT-KNN materials from 100 to $400{ }^{\circ} \mathrm{C}$.

Compared with soft PZT, which has a resistivity in the order of magnitude of $10^{12} \Omega \mathrm{m}$ at room temperature, the resistivity obtained for the BNT-BT-KNN materials at $100{ }^{\circ} \mathrm{C}$ is comparably high as it lies in the range of $10^{11}-10^{12} \Omega \mathrm{m}{ }^{7}$. For all compositions, the resistivity drops exponentially showing Arrhenius behavior with predominantly linear curves in the logarithmic plot against inverse absolute temperature. The activation energy $E_{a}$ for the electrical conductivity is $0.82 \mathrm{eV}(9 \mathrm{KNN}), 0.74 \mathrm{eV}(12 \mathrm{KNN})$, $1.04 \mathrm{eV}(15 \mathrm{KNN})$, and $0.77 \mathrm{eV}(18 \mathrm{KNN})$ in the range from 100 to $300{ }^{\circ} \mathrm{C}$. At $300{ }^{\circ} \mathrm{C}$ the resistivity is in the order of magnitude of $10^{8} \Omega \mathrm{m}$, outperforming PZT5A with 1.9 $\times 10^{7} \Omega \mathrm{m}, 0.36 \mathrm{BiScO}_{3}-0.64 \mathrm{PbTiO}_{3}($ BSPT64) with 2.4 $\times 10^{6} \Omega \mathrm{m}$ or $(\mathrm{Pb}, \mathrm{Ba}) \mathrm{Nb}_{2} \mathrm{O}_{6}$ with $10^{5} \Omega \mathrm{m}$. ${ }^{7,16}$

The time dependence of a discharging process of a capacitor is determined by the time constant $\tau$ according to Eq. (1).

$$
Q(t)=Q_{0} \exp \left(-\frac{t}{\tau}\right)
$$

Here $Q(t)$ is the charge at time $t$ and $Q_{0}$ is the initial charge. The time constant $\tau$ is defined as

$$
\tau=R \cdot C
$$

with the resistance $R$ and the capacitance $C$. At $t=\tau$ the capacitance drops to $\mathrm{e}^{-1}(\approx 37 \%)$ of the initial value, and hence $R C$ is a measure for the quality of a material to maintain its

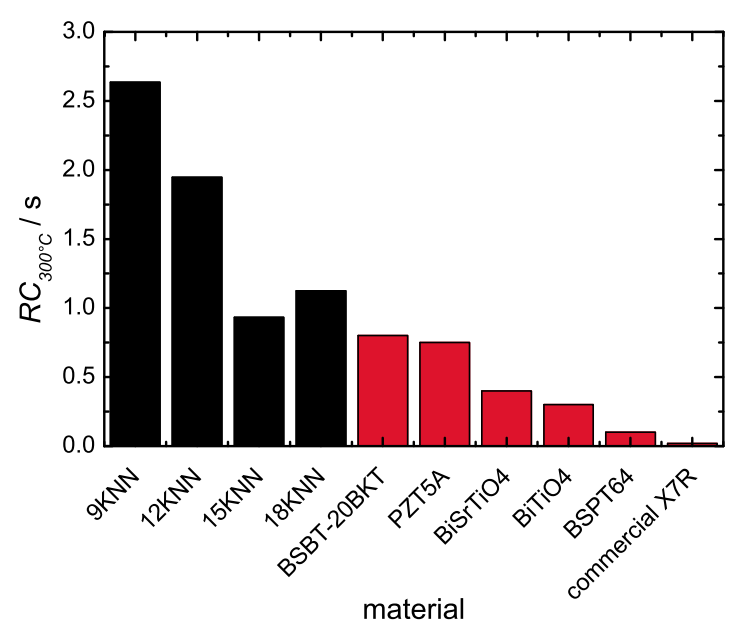

FIG. 6. (Color online) Comparison of time constants at $300{ }^{\circ} \mathrm{C}$ with BSBT20BKT (Ref. 14), PZT5A (Ref. 16), $\mathrm{BiSrTiO}_{4}$ (Ref. 14), $\mathrm{BiTiO}_{3}$ (Ref. 14), BSPT64 (Ref. 16), and commercial X7R (Ref. 14).

charge. Therefore, a high $R C$ value is synonymous for high capacitance and high resistance at the same time. Figure 6 provides a comparison of the $R C$ value at $300{ }^{\circ} \mathrm{C}$ for four BNT-BT-KNN compositions with reference to other potential candidates for high temperature dielectrics.

The addition of $\mathrm{KNN}$ reduces the $R C$ constant at $300{ }^{\circ} \mathrm{C}$ from $2.64 \mathrm{~s}$ for $9 \mathrm{KNN}$ to $1.13 \mathrm{~s}$ for $18 \mathrm{KNN}$. These values are comparably high surpassing those of other materials such as $0.8\left(0.4 \mathrm{BiScO}_{3}-0.6 \mathrm{BaTiO}_{3}\right)-0.2\left(\mathrm{Bi}_{1 / 2} \mathrm{~K}_{1 / 2}\right) \mathrm{TiO}_{3} \quad$ (BSBT20BKT), PZT5A or BSPT64. The high $R C$ values of BNTBT-KNN outperform materials with toxic elements such as lead or expensive elements such as scandium and beyond that BNT-BT-KNN features the aforementioned high permittivity over a broad temperature range. Tailoring both resistivity and $R C$ constant further by dopants as already demonstrated for other material systems is encouraged for the future. ${ }^{16,26,27}$

As already discussed, the reason behind the broad plateau in temperature dependent permittivity appears to be due to two distinct dielectric anomalies that are gradually smeared into each other as $\mathrm{KNN}$ content increases. Of course, the physical origin behind these two anomalies has to be clarified in order to fully understand and further optimize these materials. A similar characteristic of $\varepsilon(T)$ is already known from the parent pseudobinary BNT-BT system, which also shows two nearby local maxima though very different in magnitude. ${ }^{19,28}$

High-temperature in situ XRD measurements were performed from room temperature up to $300{ }^{\circ} \mathrm{C}$ for $18 \mathrm{KNN}$. No obvious noncubic distortion was detected within the analyzed temperature range. However, the changes in intensity indicate that there are at least two successive structural changes taking place. Note that a discontinuous change in the intensity of (110) pc peak (the subscript "pc" here refers to pseudocubic) is clearly seen in the temperature range of about $150-240{ }^{\circ} \mathrm{C}$ in Fig. 7.

Hinterstein et $a l .{ }^{29}$ demonstrated by combining neutron with XRD techniques that the introduction of KNN to BNT6BT stabilizes the high temperature $\mathrm{P} 4 \mathrm{bm}$ phase at room temperature, the lattice distortion of which is so small $[\mathrm{c} / \mathrm{a}$ 


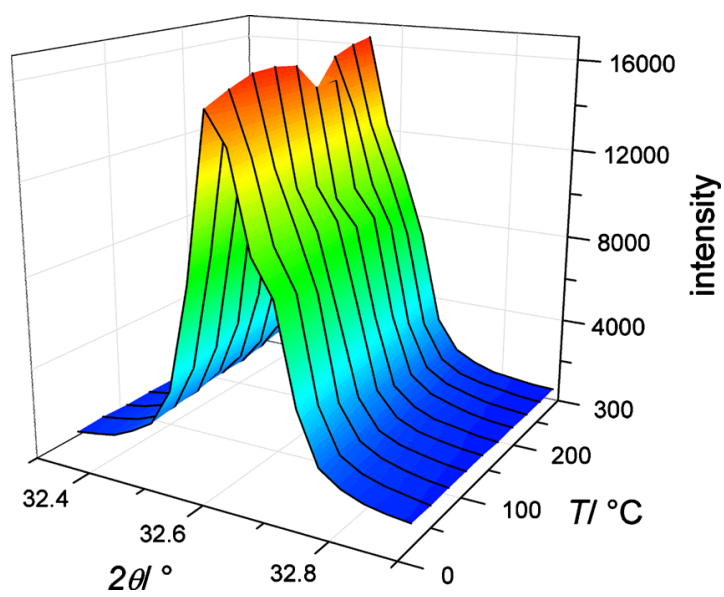

FIG. 7. (Color online) The (110) reflection for $18 \mathrm{KNN}$ remains virtually unchanged from 30 to $300{ }^{\circ} \mathrm{C}$ besides minor fluctuations in intensity and a shift in the reflex due to thermal expansion (note: diffraction pattern is collected from $\mathrm{Cu} K \alpha 1$ and $\mathrm{Cu} K \alpha 2$ wavelength).

$\approx 1.000(3)]$ that the phase can only be assigned to be tetragonal from the presence of superlattice reflection, which is properly detectable only by neutron diffraction. In addition, Webber et $a l .{ }^{30}$ showed that there is an additional phase $P 4 / \mathrm{mbm}$ (or $P 4 / \mathrm{mmm}$ ), which is paraelectric but ferroelastic, between the tetragonal $P 4 b m$ and the cubic $P m \overline{3} m$ in the BNT-6BT system. It is thus suggested that the structural evolution in $18 \mathrm{KNN}$ is given in terms of the XRD length scale as

$$
\begin{aligned}
\text { P4bm(FE/FEla }) & \sim 160^{\circ} \mathrm{C} \\
& \rightarrow 254 / \mathrm{mbm}(\text { PE } / \text { FEla }) \\
& \rightarrow \mathrm{Pm} \overline{3} \mathrm{~m}(\text { PE/PEla }),
\end{aligned}
$$

where FE, PE, FEla, and PEla denote ferroelectric, paraelectric, ferroelastic, and paraelastic, phases, respectively. It is interesting to note that though the first dielectric anomaly of $18 \mathrm{KNN}$ (see Fig. 2) is observed below $100{ }^{\circ} \mathrm{C}$, the fact that no obvious structural change is observed from the in situ XRD study strongly supports the assumption that BNT-BT-KNN is a relaxor. ${ }^{22}$ It is interesting to note that the actual structure change implied by the XRD study at about $160{ }^{\circ} \mathrm{C}$ is closely correlated with the temperature regime where dielectric dispersion disappears with an inflection point in the temperature-dependent dielectric permittivity data. However, any physical reasoning for the correlation warrants further systematic investigations.

\section{CONCLUSIONS}

Potential compositions for high temperature dielectric applications were developed in a pseudoternary lead-free BNT-BT-KNN system. These commercially viable costeffective materials provide not only temperature insensitivity but also a wide operational temperature range. Among the studied compositions, $18 \mathrm{KNN}$ was shown to offer $>270{ }^{\circ} \mathrm{C}$ (from 43 to $319^{\circ} \mathrm{C}$ ) of reliable operation temperature window and $\Delta \varepsilon / \varepsilon_{150{ }^{\circ} \mathrm{C}}<10 \%$ with concurrent permittivity val- ues exceeding 2000. Furthermore, its resistivity is comparatively high throughout the measured temperature range with an $R C$ constant of about $1 \mathrm{~s}$ at $300{ }^{\circ} \mathrm{C}$. We suggest that the materials presented render a good starting point for the development of high-capacitance, cost-effective capacitors for high-temperature application beyond $200{ }^{\circ} \mathrm{C}$.

\section{ACKNOWLEDGMENTS}

This work was financially supported by the Deutsche Forschungsgemeinschaft (DFG) under SFB 595/A1.

${ }^{1}$ C. A. Randall, H. Ogihara, J.-R. Kim, G.-Y. Yang, C. S. Stringer, S. Trolier-McKinstry, and M. Lanagan, Proceedings of the IEEE Pulsed Power Conference 2009, Washington, DC, 28 June-2 July 2009, p. 346.

${ }^{2}$ A. Nishino, J. Power Sources 60, 137 (1996).

${ }^{3}$ A. N. Hammoud and I. T. Myers, Proceedings of the Annual Report Conference on Electrical Insulation and Dielectric Phenomena, Leesburg, VA, 29 October-2 November 1989, p. 459.

${ }^{4}$ R. S. Demcko, Proceedings of the IEEE Electronics Components Conference, Los Angeles, CA, 9-11 May 1988, p. 390.

${ }^{5}$ R. R. Grzybowski and B. Gingrich, ASME J. Eng. Gas Turbines Power 121, 622 (1999).

${ }^{6}$ R. W. Johnson, J. L. Evans, P. Jacobsen, J. R. Thompson, and M. Christopher, IEEE Trans. Electron. Packag. Manuf. 27, 164 (2004).

${ }^{7}$ T. R. Shrout, R. Eitel, and C. A. Randall, in Piezoelectric Materials in Devices, edited by N. Setter (EPFL, Swiss Federal Institute of Technology, Lausanne, 2002), p. 413.

${ }^{8}$ Y. Yuan, S. R. Zhang, X. H. Zhou, B. Tang, and B. Li, J. Electron. Mater. 38, 706 (2009).

${ }^{9}$ T. Li, L. T. Li, Y. Kou, and Z. L. Gui, J. Mater. Sci. Lett. 19, 995 (2000).

${ }^{10}$ H. Beltrán, N. Maso, E. Cordoncillo, and A. R. West, J. Electroceram. 18, 277 (2007).

${ }^{11}$ A. Yializis, G. L. Powers, and D. G. Shaw, IEEE Trans. Compon., Hybrids, Manuf. Technol. 13, 611 (1990).

${ }^{12}$ C. J. Stringer, T. R. Shrout, and C. A. Randall, J. Appl. Phys. 101, 054107 (2007).

${ }^{13}$ K. Bridger, A. V. Cooke, and W. A. Schulze, U.S. Patent No. US7,697,263 B2 (13 April 2010).

${ }^{14}$ J. B. Lim, S. J. Zhang, N. Kim, and T. R. Shrout, J. Am. Ceram. Soc. 92, 679 (2009).

${ }^{15}$ H. L. Du, W. C. Zhou, F. Luo, D. M. Zhu, S. B. Qu, Y. Li, and Z. B. Pei, J. Appl. Phys. 104, 044104 (2008).

${ }^{16}$ S. Zhang, E. F. Alberta, R. E. Eitel, C. A. Randall, and T. R. Shrout, IEEE Trans. Ultrason. Ferroelectr. Freq. Control 52, 2131 (2005).

${ }^{17}$ S. T. Zhang, A. B. Kounga, E. Aulbach, H. Ehrenberg, and J. Rödel, Appl. Phys. Lett. 91, 112906 (2007).

${ }^{18}$ S. T. Zhang, A. B. Kounga, W. Jo, C. Jamin, K. Seifert, T. Granzow, J. Rödel, and D. Damjanovic, Adv. Mater. 21, 4716 (2009).

${ }^{19}$ T. Takenaka, K. Maruyama, and K. Sakata, Jpn. J. Appl. Phys., Part 130 , 2236 (1991).

${ }^{20}$ F. Cordero, F. Craciun, F. Trequattrini, E. Mercadelli, and C. Galassi, Phys. Rev. B 81, 144124 (2010).

${ }^{21}$ L. E. Cross, Ferroelectrics 76, 241 (1987).

${ }^{22}$ G. A. Samara, J. Phys.: Condens. Matter 15, R367 (2003).

${ }^{23}$ A. A. Bokov and Z. G. Ye, J. Mater. Sci. 41, 31 (2006).

${ }^{24}$ H. Qian and L. A. Bursill, Int. J. Mod. Phys. B 10, 2007 (1996).

${ }^{25}$ G. Y. Yang, E. C. Dickey, C. A. Randall, D. E. Barber, P. Pinceloup, M. A. Henderson, R. A. Hill, J. J. Beeson, and D. J. Skamser, J. Appl. Phys. 96, 7492 (2004).

${ }^{26}$ W. Hofman, S. Hoffmann, and R. Waser, Thin Solid Films 305, 66 (1997).

${ }^{27}$ D. Dimos, R. W. Schwartz, and S. J. Lockwood, J. Am. Ceram. Soc. 77, 3000 (1994).

${ }^{28}$ T. Oh and M. H. Kim, Mater. Sci. Eng., B 132, 239 (2006).

${ }^{29}$ M. Hinterstein, M. Knapp, M. Hölzel, W. Jo, A. Cervellino, and H. Ehrenberg, J. Appl. Crystallogr. 43, 1314 (2010).

${ }^{30}$ K. G. Webber, Y. Zhang, W. Jo, J. E. Daniels, and J. Rödel, J. Appl. Phys. 108, 014101 (2010). 